Their criteria for low serum $\operatorname{Ig}$ A were, however, based on a reference range from a different laboratory.

In attempting to analyse the relation between febrile convulsions and $\operatorname{IgA}$ deficiency two approaches are possible, one of which would be to examine the incidence of febrile convulsions in a group of children with low serum IgA or selective IgA deficiency and compare this with a control population. An alternative approach is to measure IgA values in a group of children presenting with febrile convulsions and compare these with a reference range, and this has been our method. Lewis $e t$ al performed a similar study on 49 children presenting with febrile convulsions, ${ }^{3}$ but again used a reference range from another laboratory. Our study shows no difference between mean age adjusted IgA values from 47 children with febrile convulsions and a large normal population, but five children had serum IgA less than $0.1 \mathrm{~g} / \mathrm{l}$ by nephelometry. It may be that in some children low serum $\operatorname{IgA}$ is associated with susceptibility to febrile convulsions.
We thank the staff of the Haematology Department, Mr H Ip, D G Altman, Dr M M Liberman, and Dr T Stacey. This work was supported by the Medical Research Council.

References

' Savilahti E. Pelkonen P. Clinical findings and intestinal immunoglobulins in children with partial IgA deficiency. Acta Paediatr Scand 1979:68:513-9.

${ }^{2}$ Seager J, Jamison DL. Wilson J. Hayward AR. Soothill JF. IgA deficiency, epilepsy and phenytoin treatment. Lancet $1975 ;$;i: $632-5$.

${ }^{3}$ Lewis HM, Valman HB, Webster ADB, Tyrell DAJ. Viruses in febrile convulsions (letter). Lancet 1980;ii:150.

${ }^{4}$ Asherson GL, Webster ADB. Diagnosis and treatment of immunodeficiency diseases. Oxford: Blackwell Scientific Publications, 1980.

'Isaacs D, Altman DG, Tidmarsh CE, Valman HB, Webster ADB. Serum immunoglobulin concentrations in pre-school children measured by laser nephelometry: reference ranges for IgG. IgA and IgM. J Clin Pathol 1983;36:1193-6.

6 DeGast G-C, Platts-Mills TAE. Functional studies on lymphocytes in adult human bone marrow II. Isolated surface IgMpositive cells. J Immunol 1979:122:285-90.

Correspondence to Dr David Isaacs, Department of Paediatrics, John Radcliffe Hospital, Headington, Oxford OX3 9DU.

Received 12 November 1983

\title{
Effect of exogenous surfactant on total respiratory system compliance
}

\author{
A D MILNER, H VYAS, AND I E HOPKIN
}

Department of Neonatal Medicine and Surgery, City Hospital, Nottingham

SUMMARY We measured total respiratory system compliance (Crs) before and after instilling $25 \mathrm{mg}$ artificial surfactant in $1 \mathrm{ml}$ saline down the endotracheal tube of preterm babies requiring resuscitation at birth, and compared results with data from 6 similar babies receiving saline only. Surfactant did not produce a significant improvement in Crs.

The role of exogenous surfactant in prevention and treatment of idiopathic respiratory distress syndrome (IRDS) remains controversial. Giving surfactant, derived from either animal lungs ${ }^{1}$ or human amniotic fluid, ${ }^{2}$ to a small number of babies requiring ventilatory support for IRDS, led to dramatic improvement in blood gas values. The improvement could however be due to the relatively large volumes of fluid instilled down the endotracheal tube or to the period of manual ventilation by bag using $100 \%$ oxygen. In a recent study, we were unable to show any improvement in either compliance or blood gases when artificial surfactant was insufflated down the endotracheal tube of 10 similar babies. ${ }^{3}$ On the other hand, Morley et $a l^{4}$ reported trial results suggesting that surfactant powder instilled down the endotracheal tube of preterm babies requiring resuscitation at birth led to a significant reduction in mortality. This finding was not, however, confirmed by Wilkinson et al in a controlled trial on a small number of babies. ${ }^{5}$ To resolve this question we have been carrying out a controlled trial in conjunction with Dr Morley and his colleagues to assess the prophylactic value of instilling artificial surfactant $\quad(70 \%$ dipalmitoylphosphatidylcholine and $30 \%$ unsaturated phosphatidylglycerol) into the upper airways of preterm babies at birth. We report here the results of compliance measurements obtained before and after the instillation of placebo or surfactant in babies who failed to breathe spontaneously and required intubation.

\section{Methods}

Fifty eight babies born with a gestational age of less than 34 weeks were included in the main study. 
Table Clinical details and results of lecithin sphingomyelin $(L / S)$ ratios, shake tests, and total respiratory system compliance $(\mathrm{Crs})$ before and after treatment

\begin{tabular}{|c|c|c|c|c|c|}
\hline \multirow[t]{2}{*}{ Case No } & \multirow{2}{*}{$\begin{array}{l}\text { Gestation } \\
\text { (weeks) }\end{array}$} & \multirow{2}{*}{$\begin{array}{l}\text { Birthweight } \\
(k g)\end{array}$} & \multirow{2}{*}{$\begin{array}{l}\text { L/S ratio } \\
\text { (Shake test) }\end{array}$} & \multicolumn{2}{|c|}{$\mathrm{Crs}\left(\mathrm{ml} / \mathrm{cmH} \mathrm{H}_{2} \mathrm{O}\right)$} \\
\hline & & & & $\begin{array}{l}\text { Before } \\
\text { treatment }\end{array}$ & $\begin{array}{l}\text { After } \\
\text { treatment }\end{array}$ \\
\hline \multicolumn{6}{|c|}{ Surfactant treated group } \\
\hline 1 & 32 & $1 \cdot 64$ & $1.06(-)$ & $0 \cdot 72$ & 0.93 \\
\hline 2 & 29 & $1 \cdot 50$ & $1.76(+)$ & 0.49 & $0 \cdot 51$ \\
\hline 3 & 32 & 1.70 & $1.21(-)$ & $0 \cdot 51$ & 0.45 \\
\hline $4^{*}$ & 28 & $1 \cdot 18$ & $1.53(-)$ & $0 \cdot 34$ & $0 \cdot 56$ \\
\hline 5 & 31 & 1.25 & $1.44(-)$ & 0.66 & $0 \cdot 64$ \\
\hline 6 & 27 & 1.07 & $1.89(+)$ & $0 \cdot 32$ & $0 \cdot 29$ \\
\hline $7^{*}$ & 29 & $1 \cdot 38$ & $1.36(-)$ & $0 \cdot 35$ & $0 \cdot 36$ \\
\hline 8 & 33 & 1.02 & $2 \cdot 19(+)$ & 0.77 & 0.60 \\
\hline 9 & 33 & $1 \cdot 79$ & $2 \cdot 22(-)$ & $0 \cdot 41$ & 0.57 \\
\hline 10 & 32 & 0.92 & $2 \cdot 01(-)$ & $0 \cdot 81$ & $0 \cdot 78$ \\
\hline Mean (SD) & $30 \cdot 6(2 \cdot 17)$ & $1 \cdot 35(0 \cdot 30)$ & $1.67(0.41)$ & $0.54(0 \cdot 19)$ & $0.57(0.19)$ \\
\hline \multicolumn{6}{|c|}{ Saline treated group } \\
\hline 11 & 32 & $1 \cdot 66$ & $1.63(-)$ & 0.52 & $0 \cdot 35$ \\
\hline $12^{*}$ & 30 & $1 \cdot 76$ & $1.88(-)$ & $0 \cdot 27$ & $0 \cdot 32$ \\
\hline $13^{* t}$ & 25 & 0.84 & $1.14(-)$ & 0.07 & $0 \cdot 15$ \\
\hline $14^{* \dagger}$ & 25 & 0.78 & $1.17(-)$ & 0.49 & 0.53 \\
\hline $15^{*}$ & 33 & $2 \cdot 02$ & $3.43(+)$ & 0.61 & 0.52 \\
\hline 16 & 31 & $1 \cdot 56$ & $2 \cdot 18(-)$ & $0 \cdot 21$ & $0 \cdot 69$ \\
\hline Mean (SD) & $29.5(3.50)$ & $1.44(0.51)$ & $1.91(1.31)$ & $0.36(0.22)$ & $0.43(0.19)$ \\
\hline
\end{tabular}

Immediately after delivery, a sample of amniotic fluid or pharyngeal aspirate was collected for lecithin sphingomyelin ratio and shake test. Babies were then allocated by a randomised system to one of two groups and either $25 \mathrm{mg}$ of surfactant in $1 \mathrm{ml}$ of cold saline, or cold saline alone was instilled into the baby's mouth. Twenty two babies-15 in the surfactant and 7 in the saline group-who failed to breathe by two minutes, or had had a heart rate falling below $80 /$ minute before that time were transferred to our modified Vickers resuscitaire. ${ }^{6}$ Intubation was carried out using a Portex Cole tube. The endotracheal tube was connected to a $T$ piece incorporating a pneumotachograph, and a side arm leading to a pressure transducer. We were thus able to record both tidal exchange and inflation pressure.$^{6}$ Standard resuscitation procedures were used, with inflation pressures of 28 to $30 \mathrm{~cm} \mathrm{H}_{2} \mathrm{O}$ maintained for one second intervals, with an $\mathrm{F}_{\mathrm{I}} \mathrm{O}_{2}$ of 1. Once the baby's condition had improved and the heart rate had risen to above 120/minute, total respiratory system compliance (Crs) was measured by maintaining the inflation pressure for two to three seconds until the inflation volume had stabilised, and measuring the fall in volume when the pressure was released. This was performed on at least three occasions. The babies were then given further doses of either artificial surfactant $(25 \mathrm{mg})$ in saline $(1 \mathrm{ml})$ or saline alone down the endo- tracheal tube using a $2 \mathrm{ml}$ syringe. Standard resuscitation was then continued for at least two minutes and the Crs measurements were repeated.

None of the differences between the groups reached statistical significance (Student's $t$ test). Technically satisfactory Crs measurements were obtained in 10 of the treated and 6 of the control babies. Three babies (twin deliveries) were resuscitated on a second resuscitaire which did not have monitoring facilities and in three other infants the inflation pressure or flow traces were unsatisfactory for technical reasons. Clinical details and results in the 16 babies for whom measurements were successful are presented in the Table.

\section{Results}

The Crs of the surfactant treated group rose from mean (SD), $0.54(0.19) \mathrm{ml} / \mathrm{cm} \mathrm{H}_{2} \mathrm{O}$ before surfactant administration to $0.57(0.19) \mathrm{ml} / \mathrm{cm} \mathrm{H}_{2} \mathrm{O}$ after treatment (Table). The values in the saline treated group were initially lower, rising from mean (SD), 0.36 $(0.21) \mathrm{ml} / \mathrm{cmH}_{2} \mathrm{O}$ to $0.43(0.19) \mathrm{ml} / \mathrm{cmH}_{2} \mathrm{O}$. If the results from babies who had lecithin sphingomyelin ratios of less than 2.0 are analysed alone, the Crs values are mean (SD), $0.48(0.16) \mathrm{ml} /$ $\mathrm{cmH}_{2} \mathrm{O}$ before treatment and $0.53(0.2) \mathrm{ml} / \mathrm{cmH}_{2} \mathrm{O}$ after treatment in the surfactant group ( 7 babies), and $0.34(0.21) \mathrm{ml} / \mathrm{cmH}_{2} \mathrm{O}$ and $0.34(0.6) \mathrm{ml} / \mathrm{cmH}_{2} \mathrm{O}$ in the control group (4 babies). In neither of the groups did the difference between values before and after treatment reach statistical significance $(\mathrm{P}<0 \cdot 05$ by Student's $t$ test). Of the surfactant treated intubated babies, 7 developed IRDS and four died, compared with four and two in the control group respectively. Two of the babies who died in the surfactant treated group were of less than 26 weeks' gestation, and two were twins of 29 weeks, one of whom had Potter's syndrome. We were unable to measure Crs in any of these infants. The development of IRDS could not be predicted from the initial Crs value; nor was there a close relation between the initial Crs value and lecithin sphingomyelin ratio or shake test.

\section{Discussion}

In this study, we were unable to show a significant improvement in Crs after instillation of $25 \mathrm{mg}$ of artificial surfactant down the endotracheal tube of preterm babies requiring resuscitation. Although it is possible that some of the initial dose of surfactant had entered the lower respiratory tract, we think this unlikely as transferring the babies over to the resuscitation table and then placing them head down led to the fluid in the upper airway running out. We 
consider it unlikely that a larger dose of this surfactant would have produced more dramatic changes, as $25 \mathrm{mg}$ is far in excess of that required for a monolayer throughout the lung. The initial Crs values in the surfactant treated babies were marginally higher than those in the control group, reflecting perhaps the fact that the group as a whole was relatively more mature. Both groups showed a trend towards improved compliance after the instillation, probably representing improved aeration and clearance of alveolar fluid.

We conclude that giving artificial surfactant at birth does not have any immediate, dramatic effect on lung mechanics of preterm babies. The two treatment groups had similar subsequent courses, but it is not possible to state in this small series whether surfactant has a prophylactic value in IRDS in some infants.

We thank Dr Colin Morley, New Addenbrooke's Hospital Cambridge, who prcvided us with the surfactant powder. This work was funded by a grant from the Medical Research Council.

\section{References}

${ }^{1}$ Fujiwara T, Maeta H, Chida S, Morita T, Watabe Y, Abe T. Artificial surfactant therapy in hyaline membrane disease. Lancet 1980;i:55-9.

${ }^{2}$ Hallman M, Merritt TA, Schneider H, et al. Isolation of human surfactant from amniotic fluid and a pilot study of its efficacy in respiratory distress syndrome. Pediatrics 1983;71:473-82.

${ }^{3}$ Milner AD, Vyas H, Hopkin IE. Effects of artificial surfactant on lung function and blood gases in idiopathic respiratory distress syndrome. Arch Dis Child 1983;58:458-60.

${ }^{4}$ Morley CJ, Bangham AD, Miller N. Davis JH. Dry artificial lung surfactant and its effect on very premature babies. Lancet $1981 ; \mathbf{i}: 64-8$

5 Wilkinson AR, Jeffrey JA, Jenkins PA. Controlled trials of dry surfactant in preterm infants (abstract). Arch Dis Child 1982;57:802.

${ }^{6}$ Vyas H, Milner AD, Hopkin IE. Physiological responses to prolonged and slow rise inflation. $J$ Pediatr 1981;98:635-40.

Correspondence to Professor A D Milner, Department of Neonatal Medicine and Surgery, City Hospital, Hucknell Road, Nottingham NG5 1PB.

Received 21 October 1983

\title{
Febrile convulsions: electroencephalographic changes related to rectal temperature
}

\author{
P E MINCHOM AND S J WALLACE \\ University Hospital of Wales, Heath Park, Cardiff
}

SUMMARY Nine children had simultaneous continuous electroencephalographic monitoring and temperature recording immediately after febrile convulsions. Background electroencephalographic rhythms did not alter with temperature and with one exception, seizure discharges occurred only during sustained high pyrexia.

The relation between electroencephalographic and electrocardiographic changes and body temperature over periods up to 25 hours starting as soon as possible after febrile convulsions is examined. The findings are related to short term outlook.

\section{Patients and methods}

Nine children admitted to hospitals in Cardiff after febrile convulsions during 1982 were studied. All had had generalised fits that lasted less than 10 minutes and none had received diazepam.

The patients were examined clinically between 1.5 and 5 hours (mean 3.3 hours) after the convulsion. Rectal temperatures were recorded hourly using a mercury in glass thermometer. A Medilog (Oxford Instruments) four channel recorder with two electroencephalographic, one electrocardiographic, and one timing channel was used for recordings, which started from 2.75 hours to 10.5 hours (mean 4.7 hours) after the febrile convulsion and continued for 11 to 25 hours (mean $15 \cdot 8$ hours). The electroencephalographic montage used was F3-P3, F4-P4 in the 10-20 system.

The electroencephalographs were subsequently examined on the Medilog monitor display unit without reference to temperature recordings. A flow chart was composed for each child consisting of the speeds of the basic rhythms in a typical section of the tape for each hour, coinciding with the temperature recordings. Each tape was scrutinised for paroxysmal activity and a note was made of any asymmetry. Once the electroencephalograph had been analysed the temperature measurements were 